\title{
Desenvolvimento dos componentes do peso vivo de cordeiros Santa Inês e Bergamácia abatidos em diferentes pesos ${ }^{1}$
}

\section{Cristiane Leal dos Santos-Cruz ${ }^{2^{*}}$, Juan Ramon Olalquiaga Pérez ${ }^{3}$, Joel Augusto Muniz ${ }^{4}$, Christian Albert Carvalho da $\mathrm{Cruz}^{5}$, Thais Romano de Vasconcelos e Almeida ${ }^{2}$}

\author{
1 Projeto financiado pela FAPEMIG. \\ 2 Programa de Pós-graduação em Zootecnia - UFLA. \\ ${ }^{3}$ Departamento de Zootecnia, UFLA, Caixa Postal 37, CEP: 37200-000 - Lavras, MG. \\ ${ }^{4}$ Departamento de Ciências Exatas, UFLA, Caixa Postal 37, CEP: 37200-000 - Lavras, MG. \\ 5 Programa de Pós-graduação em Engenharia de Alimentos - UESB.
}

RESUMO - Objetivou-se com este estudo verificar o crescimento diferencial dos órgãos e das vísceras em relação ao peso do corpo vazio de cordeiros Santa Inês e Bergamácia. Foram utilizados 36 cordeiros machos não-castrados (24 Santa Inês e 12 Bergamácia) aos $15,25,35$ e $45 \mathrm{~kg}$ de peso vivo, confinados recebendo uma dieta com relação 20:80 de volumoso:concentrado. O estudo do crescimento relativo dos órgãos internos, das gorduras, das partes não-integrantes da carcaça, das partes da carcaça, dos componentes das cavidades abdominal e torácica foi realizado pelo modelo não-linear da equação potência $Y=\alpha X^{\beta}$, transformado logaritmicamente em um modelo linear, $\ln Y=\ln \alpha+\beta \ln X$. O fígado, pâncreas, abomaso, intestino delgado, intestino grosso e a cavidade torácica são partes do corpo vazio dos animais que apresentaram desenvolvimento precoce, enquanto o baço, a cavidade abdominal, as partes integrantes e não-integrantes da carcaça foram considerados de crescimento isogônico $(\beta=1)$; os depósitos de gordura apresentaram crescimento heterogônico positivo $(\beta>1)$. O omaso e rúmen/retículo dos cordeiros Santa Inês se desenvolvem precocemente, enquanto nos cordeiros Bergamácia se desenvolve tardiamente. O fígado, pâncreas, abomaso, intestino delgado, intestino grosso e a cavidade torácica, nas duas raças, possuem desenvolvimento precoce e o baço, a cavidade abdominal, as partes integrantes e não integrantes da carcaça possuem crescimento isogônico em relação ao peso do corpo vazio.

Palavras-chave: alometria, crescimento, ovinos

\section{Development of live weight components from Santa Inês and Bergamácia lambs slaughtered at different weights}

\begin{abstract}
This study had the objective of verifying the differential growth of carcass organs and visceras in relation to the empty body weight of Santa Ines and Bergamacia lambs. Thirty-six non-castrated male lambs, 24 Santa Ines breed and 12 Bergamacia breed, slaughtered at $15,25,35$ and $45 \mathrm{~kg}$ of live weight under feedlot system receiving a diet with forage:concentrate ratio of 20:80 were used. The study of the relative growth of internal organs, fats, carcass non-integrant parts, carcass parts and components of the abdominal and thoracic cavities was carried out by means of the non-linear model of the potency equation $Y=\alpha X^{\beta}$, linearly transformed into a linear model, $\ln Y=\ln \alpha+\beta \ln X$. Liver, pancreas, abomasum, small intestine, large intestine and thoracic cavity are parts of the empty body of the animals that presented early development, while spleen, abdominal cavity, carcass integrant and non-integrant parts presented isogonic growth $(\beta=1)$; the fat stores presented negative heterogonic growth $(\beta<1)$. The omasum and rumen/reticulum of Santa Inês lambs growth early, while in Bergamácia lambs, it grows late. Liver, pancreas, abomasum, small intestine, large intestine and thoracic cavity in both breeds present early development and spleen, abdominal cavity, carcass integrant and non-integrant parts present isogonic growth in relation to the weight of the empty body.
\end{abstract}

Key Words: allometry, growth, sheep

\section{Introdução}

As funções primárias do trato gastrintestinal e de seus órgãos acessórios são a digestão e a absorção de nutrientes essenciais para os processos metabólicos. No Brasil, existem poucos estudos sobre o desenvolvimento relativo (alométrico) do trato gastrintestinal e o tamanho dos órgãos internos de ovinos e caprinos. Perón et al.

Este artigo foi recebido em 10/8/2006 e aprovado em 2/9/2008.

Correspondências devem ser enviadas para: crislealcruz@gmail.com

${ }^{*}$ Endereço atual: DTRA/UECO/UESB - Campus Juvino Oliveira, Br 415, Km 03, Itapetinga, BA. 
(1993), Oliveira et al. (1994) e Jorge et al. (1998) desenvolveram pesquisas direcionadas ao estudo do desenvolvimento dos órgãos internos de bovinos.

Os estudos de crescimento da carcaça e dos órgãos internos normalmente são realizados em comparação ao peso corporal vazio, visto que o peso do conteúdo gastrintestinal varia amplamente, de 10 a $20 \%$ do peso vivo, de acordo com o sistema de alimentação (Geay, 1975, citado por Marques et al., 2006). De acordo com Rosa (2000), o peso relativo das partes não-integrantes da carcaça pode variar de 40 a $60 \%$ do peso vivo, conforme a raça, o sexo, a idade, o peso vivo, o tipo de parto (simples ou duplo), a categoria animal e as condições nutricionais.

$\mathrm{O}$ peso absoluto dos componentes não-carcaça normalmente aumenta com o crescimento do animal, mas os pesos relativos ao peso vivo e ao peso de corpo vazio diminuem (Sisson \& Grossman, 1986). Segundo Owens et al. (1995), o tamanho relativo dos órgãos internos é importante em trabalhos sobre exigências energéticas, uma vez que diferenças nas partes não-integrantes da carcaça podem induzir variações nos requerimentos energéticos. No entanto, de acordo com Silva et al. (1999), cordeiros abatidos com menores pesos apresentam maior proporção de componentes corporais, assim, o peso de abate é um indicativo do peso dos constituintes não-carcaça.

Segundo Drovillard et al. (1991), o peso das vísceras varia de acordo com a proporção de energia consumida. Oliveira et al. (2002) não detectou influência das dietas nos cortes comerciais, nos órgãos internos do aparelho digestivo e nos componentes corporais externos, com exceção da área de olho-de-lombo e da proporção de intestino delgado, que foram maiores nos animais que receberam a dieta controle.

Órgãos e vísceras são de desenvolvimento precoce (Marple, 1983; Berg \& Butterfield, 1976) e o fenômeno ocorre com maior intensidade em estágios iniciais da vida do animal. Isto ocorre porque o desenvolvimento é mais precoce na fase inicial da vida do animal e, com o decorrer da idade do animal, a velocidade de crescimento dos tecidos muscular e, principalmente do adiposo, se torna maior, de modo que os órgãos internos passam a representar menor proporção do peso corporal vazio.

Objetivou-se com este trabalho estudar o desenvolvimento relativo dos órgãos internos dos cordeiros das raças Santa Inês e Bergamácia dos $15 \mathrm{~kg}$ aos $45 \mathrm{~kg}$ de peso vivo.

\section{Material e Métodos}

Oexperimento foi desenvolvido no Setor de Ovinocultura da Universidade Federal de Lavras - UFLA/MG.
Foram utilizados 36 cordeiros machos não-castrados, com peso médio inicial de $15 \mathrm{~kg}$, aos 45 dias de idade ( $12 \mathrm{da}$ raça Bergamácia e 24 Santa Inês) abatidos ao atingirem 15, 25,35 e $45 \mathrm{~kg}$ de peso vivo e com as idades médias de 70; 119; 166 e 215 dias, respectivamente. Consideraram-se três repetições para os Bergamácia e seis para os Santa Inês, de modo que o cordeiro correspondeu à unidade experimental.

Os animais foram vermifugados e passaram por um período de 14 dias de adaptação à dieta. Em seguida, sob regime de confinamento, foi fornecida uma dieta total, à vontade, constituída de $20,25 \%$ de feno triturado de coastcross (Cynodon dactylon), 12,37\% de farelo de soja (Glicine max L.), 66,23\% de grão de milho (Zea mays L.), $0,85 \%$ de calcário calcítico, $0,25 \%$ de sal comum, $0,01 \%$ de suplemento mineral e $0,04 \%$ de suplemento vitamínico para ovinos, em porcentagem da MS, calculada com base nas exigências nutricionais estabelecidas pelo ARC (1980), para ganho de peso diário de $300 \mathrm{~g}$, com relação volumoso:concentrado de 20:80.

$\mathrm{O}$ abate foi realizado por atordoamento com marreta na fronte do animal, seguido de um corte na artéria carótida e nas veias jugulares, com coleta e pesagem do sangue. Após a sangria, foi feita uma abertura ao longo de toda a extensão da linha mediana ventral para a evisceração ou retirada das partes não-integrantes da carcaça. Cabeça, patas, cauda e testículo foram retirados e o trato gastrintestinal, a bexiga e a vesícula biliar, cheios e vazios, para determinação do peso corporal vazio (PCVZ).

O estudo do crescimento relativo de órgãos internos, gorduras, partes não-integrantes da carcaça, partes da carcaça e das cavidades abdominal e torácica foi realizado pelo modelo não-linear da equação potência $Y=\alpha X^{\beta}$, transformada logaritmicamente em um modelo linear, $\ln Y=\ln \alpha+\beta \ln X$ (Huxley, 1932), em que $Y=$ peso dos órgãos internos (fígado, rúmen/retículo, abomaso, omaso, intestino delgado, intestino grosso); peso das gorduras (cavitária, omental, mesentérica, perirenal); peso das partes não integrantes da carcaça - PNCAR (sangue, cabeça, patas, pele, cauda); peso das partes integrantes da carcaça - PICAR (carcaça, rins, gordura perirenal, gordura cavitária); peso da cavidade abdominal - CABD (rúmen/ retículo, omaso, abomaso, gordura omental, intestino delgado, intestino grosso, gordura mesentérica, fígado, baço e pâncreas) e peso da cavidade torácica - CTOR (traquéia, esôfago, coração e pulmões); e $\mathrm{X}=$ peso do corpo vazio (PCVZ); $\alpha=$ intercepção do logaritmo da regressão linear sobre $\mathrm{Y}$ e "b"; $\beta=$ coeficiente de crescimento relativo ou coeficiente de alometria.

As análises para obtenção dos coeficientes alométricos foram realizadas pelo Proc Reg (SAS, 2000). Para verificação 
das hipóteses de nulidade $(\beta=1)$ e alternativa $(\beta \neq 1)$, foi realizado o teste $\mathrm{t}$ (Student) $(\alpha=0,05$ e $\alpha=0,01)$. Se $\beta=1$, o crescimento foi denominado isogônico, o que indica que as taxas de desenvolvimento de $\mathrm{X}$ e $\mathrm{Y}$ foram semelhantes no intervalo de crescimento considerado. Quando $\beta \neq 1$, o crescimento foi chamado heterogônico positivo $(\beta>1)$, o que indica órgão de desenvolvimento tardio; ou negativo $(\beta<1)$, órgão de desenvolvimento precoce. Para comparação entre raças, utilizaram-se o teste de $\mathrm{F}$ e o teste $\mathrm{T}$ pelo PROCTEST COCHRAN (SAS, 2000).

\section{Resultados e Discussão}

Os pesos médios de fígado, pâncreas e baço não diferiram $(\mathrm{P}>0,05)$ entre cordeiros Santa Inês e Bergamácia (Tabela 1).
A partir do peso corporal vazio, foram determinadas equações de regressão para estimar os desenvolvimentos relativos de fígado, pâncreas e baço (Tabela 2). O fígado e o pâncreas apresentaram coeficientes alométricos que caracterizam crescimento heterogônico negativo $(\beta<1)$; além disso, de acordo com os valores de probabilidade de $\mathrm{F}$, utilizados para testar o coeficiente alométrico da equação de cada raça, não houve diferença significativa entre os cordeiros Santa Inês e Bergamácia ( $\mathrm{P}>0,05)$.

Oliveira et al. (2002), em pesquisa com ovinos alimentados com rações com dejetos de suínos, não verificaram efeito das dietas ou das raças (Santa Inês e Bergamácia) sobre o peso de traquéia, pulmão, coração, fígado e baço e da gordura visceral (omental e mesentérica) verificaram maior peso da traquéia apenas nos cordeiros da raça Santa

Tabela 1 - Pesos médios de fígado, pâncreas e baço de cordeiros Santa Inês e Bergamácia abatidos em diversos pesos

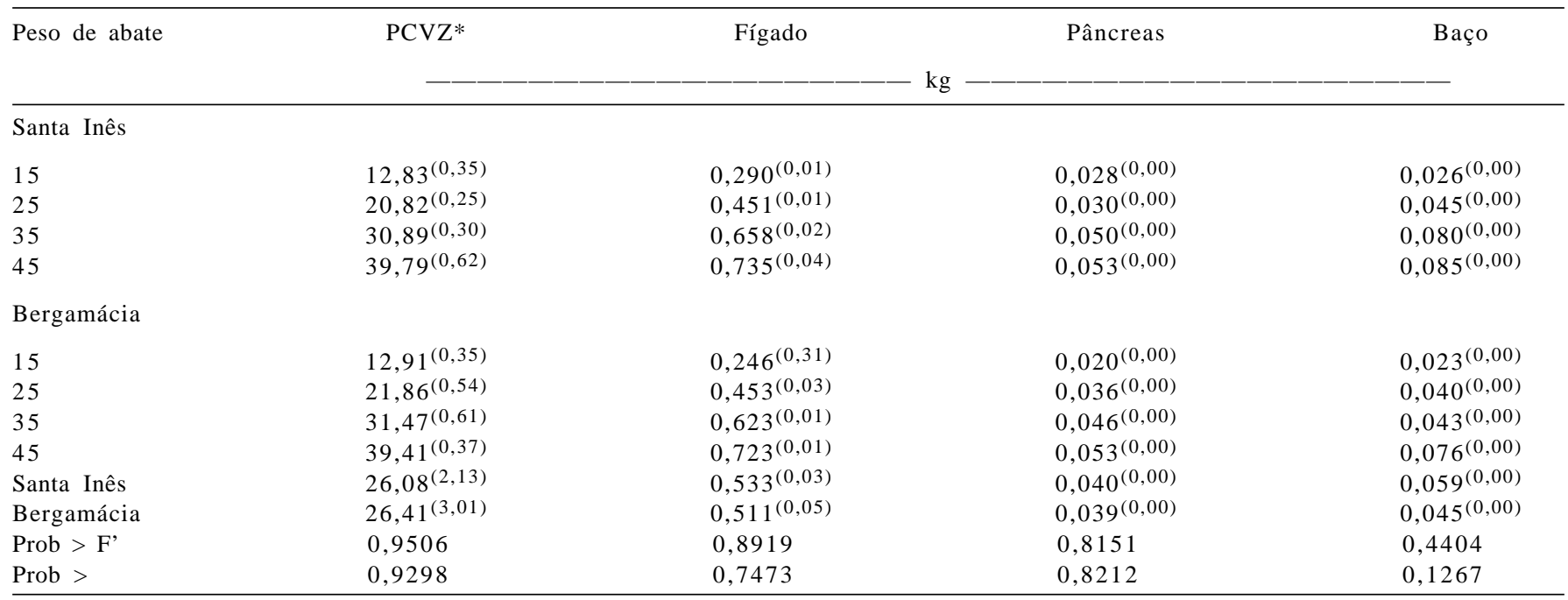

*PCVZ - peso do corpo vazio.

Tabela 2 - Coeficiente de alometria $(\beta)$ de fígado, pâncreas e baço de cordeiros Santa Inês e Bergamácia

\begin{tabular}{|c|c|c|c|c|c|}
\hline Raça & $\beta$ & Erro-padrão & $\mathrm{R}^{2}$ & Prob > Ho: $\beta=1$ & \\
\hline \multicolumn{6}{|l|}{ Fígado } \\
\hline $\begin{array}{l}\text { Santa Inês } \\
\text { Bergamácia } \\
\text { Equação geral }\end{array}$ & $\begin{array}{c}0,8494 \\
0,9814 \\
\ln Y=-3,5490+0,8911 \ln X\end{array}$ & $\begin{array}{c}0,0584 \\
0,087\end{array}$ & $\begin{array}{l}0,90 \\
0,92\end{array}$ & $\begin{array}{c}*(\beta<1) \\
\mathrm{ns}\end{array}$ & Prob > F' \\
\hline \multicolumn{6}{|l|}{ Pâncreas } \\
\hline $\begin{array}{l}\text { Santa Inês } \\
\text { Bergamácia } \\
\text { Equação geral }\end{array}$ & $\begin{array}{c}0,6398 \\
0,9837 \\
\ln Y=-5,7016+0,7511 \ln X\end{array}$ & $\begin{array}{l}0,1811 \\
0,1946\end{array}$ & $\begin{array}{l}0,36 \\
0,71\end{array}$ & $\begin{array}{c}*(\beta<1) \\
\mathrm{ns}\end{array}$ & \\
\hline \multicolumn{6}{|l|}{ Baço } \\
\hline $\begin{array}{l}\text { Santa Inês } \\
\text { Bergamácia } \\
\text { Equação geral }\end{array}$ & $\begin{array}{c}1,0921 \\
0,9594 \\
\ln Y=-6,3469+1,0437 \ln X\end{array}$ & $\begin{array}{l}0,1027 \\
0,1579\end{array}$ & $\begin{array}{l}0,82 \\
0,78\end{array}$ & $\begin{array}{l}\mathrm{ns} \\
\mathrm{ns}\end{array}$ & \\
\hline
\end{tabular}

** $\mathrm{P}<0,01 ; * \mathrm{P}<0,05$. 
Inês. Resultados semelhantes para pulmão e baço $(0,421 \mathrm{e}$ $0,061 \mathrm{~kg}$, respectivamente), foram descritos por Kouakou et al.(1997).

Osório et al. (1995), em experimento com cordeiros da raça Crioula, encontraram para o baço $(\beta=1,11)$ e para o fígado $(\beta=1,0)$ coeficientes alométricos iguais a 1 e comprovaram intensidade de crescimento igual ou superior à do peso do corpo vazio. Neste trabalho, o fígado $(\beta<0,84$; $\beta=0,98)$ e pâncreas $(\beta<0,63 ; \beta=0,98)$ apresentaram crescimento heterogônico negativo e isogônico, para os cordeiros Santa Inês e Bergamácia, respectivamente. No entanto, o baço das duas raças estudadas apresentou crescimento semelhante ao encontrado por Osório et al. (1995).

Conforme demonstrado na Figura 1, à medida que houve desenvolvimento do corpo vazio dos cordeiros, o fígado apresentou crescimento heterogônico negativo $(\beta<0,89)$, o que não diferiu entre as raças separadamente. $O$ mesmo comportamento foi observado para o baço $(\beta=1,04)$ quando os dados foram analisados de forma geral.

O desenvolvimento dos órgãos ocorre com a mesma intensidade nas duas raças, uma vez que não houve diferença significativa entre os resultados com os testes $\mathrm{F}$ e $\mathrm{T}$ (Tabela 3). No entanto, na análise do desenvolvimento relativo destes constituintes corporais, os coeficientes alométricos do rúmen/retículo e omaso diferiram entre raças.

O retículo/rúmen apresentou desenvolvimento precoce $(\beta<0,6848)$ e tardio $(\beta>1,1175)$ nas raças Santa Inês e Bergamácia, respectivamente, possivelmente em virtude do ajuste da equação alométrica aos valores observados (Figura 2 e Tabela 5). O desenvolvimento do rúmen/retículo da raça Bergamácia apresentou ritmo de crescimento mais intenso após $20 \mathrm{~kg}$ de peso do corpo vazio, enquanto na raça Santa Inês foi mais precoce $(\beta<0,68)$. Em relação ao omaso, a raça Bergamácia também apresentou desenvolvimento tardio $(\beta>1,515)$; o ritmo de crescimento passou a ser acelerado a partir de $30 \mathrm{~kg}$ de peso corporal vazio (Figura 3).

Os intestinos delgado $(\beta<0,430)$ e grosso $(\beta<0,678)$ apresentaram crescimento heterogônico negativo, ou seja, com ritmo de crescimento foi mais intenso no início do desenvolvimento do animal (Tabela 4). Não houve diferença entre as raças quanto ao tipo de crescimento do

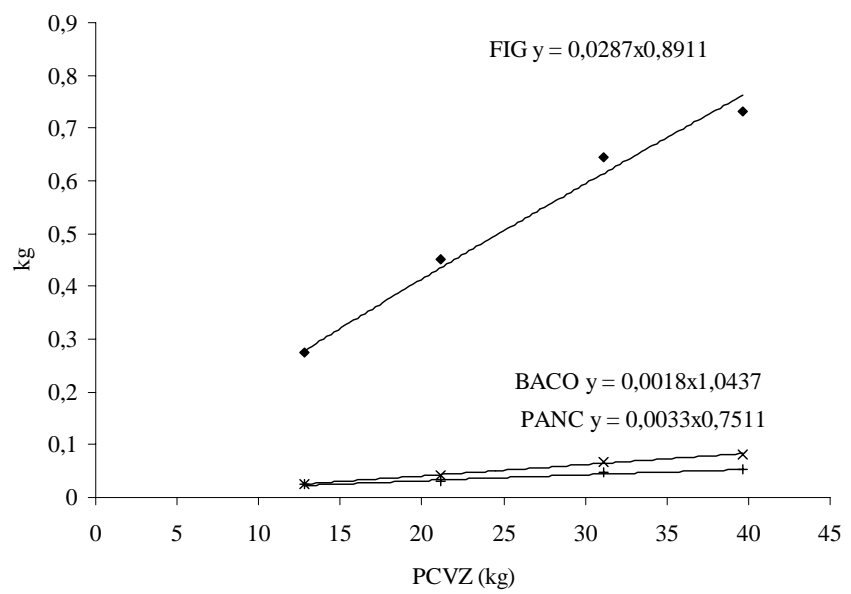

Figura 1 - Equação geral do crescimento alométrico do fígado, pâncreas e baço de cordeiros Santa Inês e Bergamácia de acordo com o peso de corpo vazio (PCVZ).

Tabela 3 - Pesos do rúmen/retículo, omaso, abomaso, intestino delgado e intestino grosso de cordeiros Santa Inês e Bergamácia abatidos com diferentes pesos

\begin{tabular}{|c|c|c|c|c|c|c|}
\hline Peso de abate & Peso de corpo vazio* & Rúmen/ Retículo & Omaso & Abomaso & Intestino delgado & Intestino grosso \\
\hline \multicolumn{7}{|l|}{ Santa Inês } \\
\hline 15 & $12,83^{(0,35)}$ & $0,336^{(0,01)}$ & $0,071^{(0,04)}$ & $0,086^{(0,00)}$ & $0,458^{(0,02)}$ & $0,220^{(0,00)}$ \\
\hline 25 & $20,82^{(0,25)}$ & $0,533^{(0,02)}$ & $0,048^{(0,00)}$ & $0,106^{(0,00)}$ & $0,635^{(0,00)}$ & $0,291^{(0,00)}$ \\
\hline 35 & $30,89^{(0,30)}$ & $0,655^{(0,02)}$ & $0,073^{(0,00)}$ & $0,133^{(0,00)}$ & $0,695^{(0,03)}$ & $0,401^{(0,02)}$ \\
\hline 45 & $39,79^{(0,62)}$ & $0,741^{(0,03)}$ & $0,076^{(0,00)}$ & $0,146^{(0,00)}$ & $0,701^{(0,04)}$ & $0,423^{(0,03)}$ \\
\hline \multicolumn{7}{|l|}{ Bergamácia } \\
\hline 15 & $12,91^{(0,35)}$ & $0,220^{(0,05)}$ & $0,016^{(0,00)}$ & $0,070^{(0,00)}$ & $0,413^{(0,04)}$ & $0,163^{(0,03)}$ \\
\hline 25 & $21,86^{(0,54)}$ & $0,490^{(0,02)}$ & $0,050^{(0,00)}$ & $0,113^{(0,00)}$ & $0,703^{(0,03)}$ & $0,306^{(0,02)}$ \\
\hline 35 & $31,47^{(0,61)}$ & $0,616^{(0,12)}$ & $0,060^{(0,00)}$ & $0,120^{(0,01)}$ & $0,630^{(0,04)}$ & $0,396^{(0,02)}$ \\
\hline 45 & $39,41^{(0,37)}$ & $0,743^{(0,03)}$ & $0,086^{(0,00)}$ & $0,140^{(0,01)}$ & $0,850^{(0,16)}$ & $0,403^{(0,02)}$ \\
\hline \multicolumn{7}{|l|}{ Raça } \\
\hline Santa Inês & $26,08^{(2,13)}$ & $0,566^{(0,03)}$ & $0,067^{(0,01)}$ & $0,118^{(0,00)}$ & $0,622^{(0,02)}$ & $0,334^{(0,02)}$ \\
\hline Bergamácia & $26,41^{(3,01)}$ & $0,517^{(0,06)}$ & $0,053^{(0,00)}$ & $0,110^{(0,00)}$ & $0,649^{(0,02)}$ & $0,317^{(0,03)}$ \\
\hline Prob > F' & 0,9506 & 0,3477 & 0,0214 & 0,8004 & 0,1178 & 0,6410 \\
\hline Prob > & 0,9298 & 0,4864 & 0,3131 & 0,4756 & 0,6962 & 0,6630 \\
\hline
\end{tabular}

*PCVZ - peso do corpo vazio. 


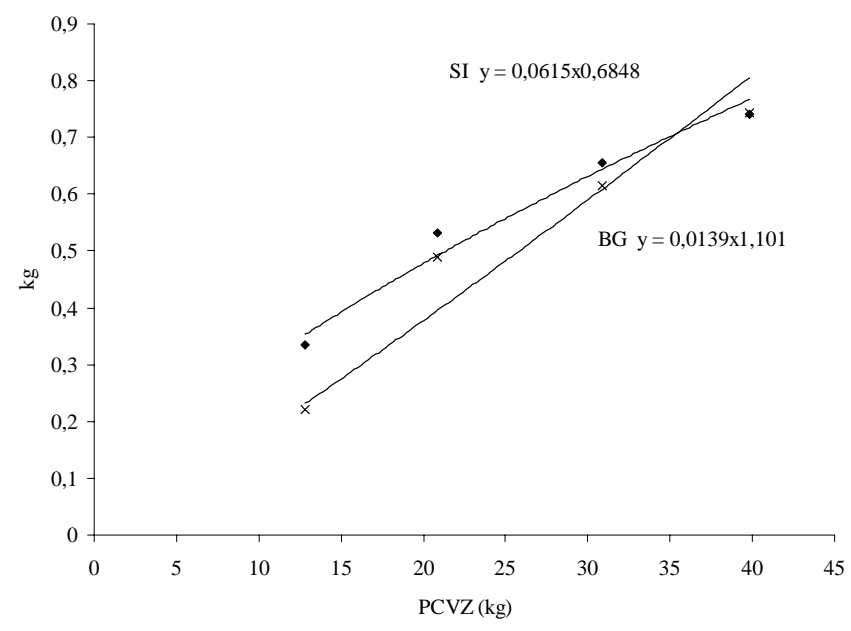

Figura 2 - Crescimento alométrico do retículo/rúmen dos cordeiros Santa Inês e Bergamácia em relação ao peso corporal vazio (PCVZ).

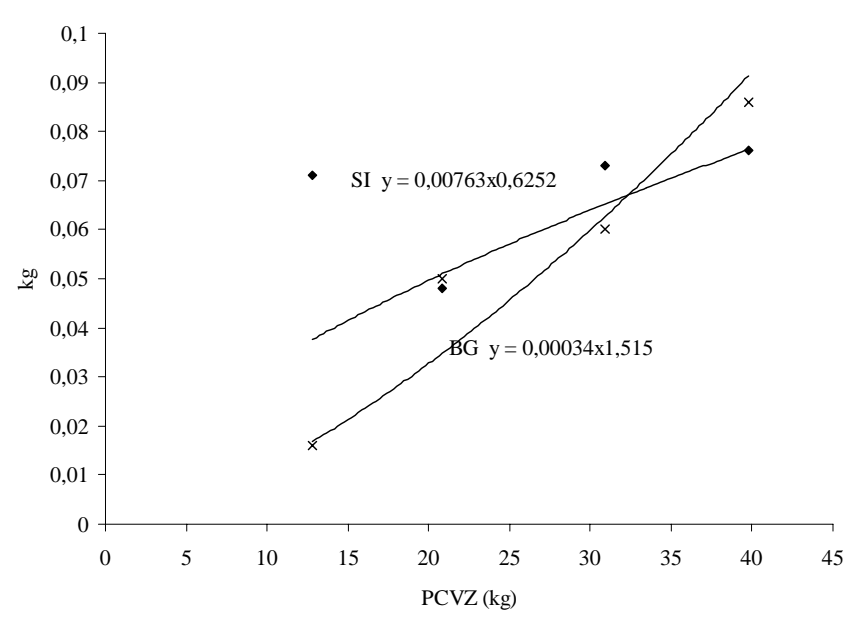

Figura 3 - Crescimento alométrico do omaso de cordeiros Santa Inês (SI) e Bergamácia (BG) em relação ao peso corporal vazio.

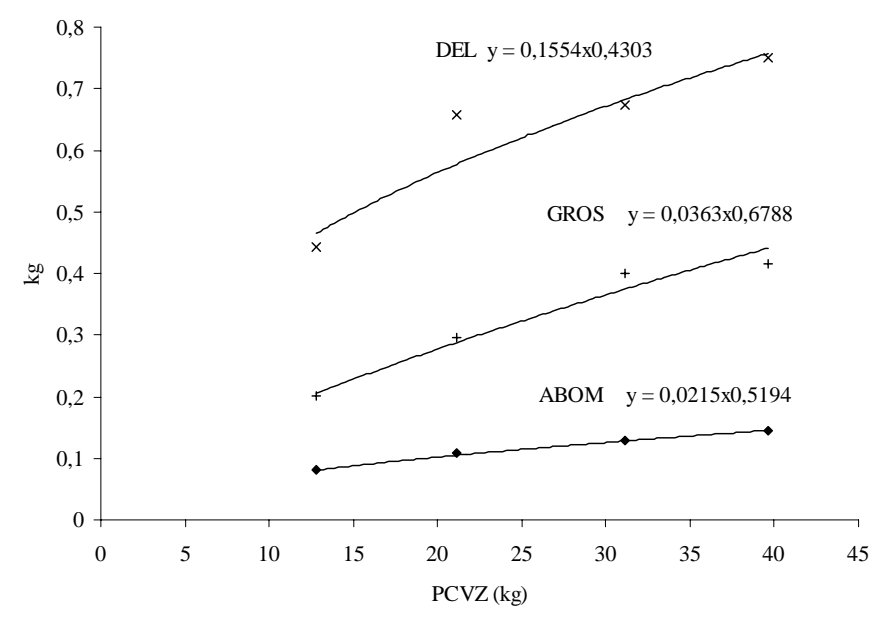

Figura 4 - Crescimento alométrico do abomaso (ABOM), intestino delgado (DEL) e intestino grosso (GROS) de ovinos Santa Inês e Bergamácia em relação ao peso corporal vazio (PCVZ).
Tabela 4 - Coeficiente de alometria ( $\beta$ ) do intestino delgado e grosso de cordeiros Santa Inês (SI) e Bergamácia (BG)

\begin{tabular}{|c|c|c|c|c|c|}
\hline \multirow[b]{2}{*}{ Raça } & \multicolumn{4}{|c|}{ Intestino delgado } & \multirow[b]{2}{*}{ Prob > F' } \\
\hline & $\beta$ & ep & $\mathrm{R}^{2}$ & $\begin{array}{r}\text { Prob }>|T| \\
\text { Ho: } \beta=1\end{array}$ & \\
\hline Santa Inês & 0,3694 & 0,0831 & 0,47 & $*(\beta<1)$ & \multirow{2}{*}{0,2394} \\
\hline Bergamácia & 0,5552 & 0,1430 & 0,60 & $*(\beta<1)$ & \\
\hline \multirow[t]{2}{*}{ Equação geral } & \multicolumn{4}{|c|}{$\ln Y=-1,8613+0,4303 \ln X$} & \\
\hline & \multicolumn{4}{|c|}{ Intestino grosso } & \multirow{3}{*}{0,0729} \\
\hline Santa Inês & 0,5854 & 0,067 & 0,77 & $* * \quad(\beta<1)$ & \\
\hline Bergamácia & 0,8684 & 0,1718 & 0,71 & $*(\beta<1)$ & \\
\hline
\end{tabular}

Equação geral $\ln Y=-3,3159+0,6788 \ln X$

** $\mathrm{P}<0,01 ; * \mathrm{P}<0,05$.

abomaso e intestino delgado grosso (Figura 4). O desenvolvimento dos intestinos diminui proporcionalmente ao aumento do peso de abate, provavelmente em razão do alto crescimento do animal do nascimento ao desmame, o que pode confirmar o desenvolvimento precoce, ou seja, o corpo dos cordeiros cresceu de forma mais intensa que o órgão.

Esse desenvolvimento precoce ocorreu com a maioria dos órgãos internos, como abomaso, intestino delgado e grosso (Figura 4) que apresentaram, respectivamente, os seguintes coeficientes de alometria: $\beta<0,519 ; 0,430$ e 0,678 .

Pires et al. (2000) verificaram que as proporções de retículo/rúmen, omaso e abomaso, quando somadas, apresentaram maior desenvolvimento após o desmame e atribuíram a esse resultado à retirada do leite do cordeiro, forçando-os a ingerir sólidos, e promovendo o desenvolvimento mais rápido do rúmen e retículo.

De acordo com Oh et al. (1972), em cordeiros de 56 a 150 dias de idade, os pesos relativos de retículo/rúmen, omaso, abomaso e intestino delgado, quando somados, modificam-se muito pouco durante os primeiros 28 dias de vida pós-natal; entretanto, a proporção em relação ao peso do trato gastrintestinal total aumenta e a de intestino delgado diminui. Lyford (1993) afirma que o pré-estômago do cordeiro aumenta 0,4 a $1,7 \%$, e o intestino delgado, 1,1 a $2,6 \%$ do peso corporal entre o nascimento e a nona semana de idade.

Os coeficientes de crescimento dos componentes do corpo, para todos os pesos estudados, permitem concordar com as afirmações de Berg \& Butterfield (1976), de modo que os órgãos mais vitais têm maior crescimento em uma fase precoce na vida do animal. Segundo Huidobro \& Villapadierma (1992), a classificação, de acordo com o 
Tabela 5 - Coeficiente de alometria $(\beta)$ para o rúmen/retículo, abomaso e omaso de cordeiros Santa Inês e Bergamácia

\begin{tabular}{|c|c|c|c|c|c|}
\hline \multirow[b]{2}{*}{ Raça } & \multicolumn{4}{|c|}{ Rúmen/retículo } & \multirow[b]{2}{*}{ Prob > F' } \\
\hline & $\beta$ & ep & $\mathrm{R}^{2}$ & $\begin{array}{c}\text { Prob }>|T| \\
\text { Ho: } \beta=1\end{array}$ & \\
\hline Santa Inês & 0,6848 & 0,0548 & 0,87 & $* * \quad(\beta<1)$ & \multirow[t]{2}{*}{$0,0060 \quad\left(^{* *}\right)$} \\
\hline Bergamácia & 1,1175 & 0,1813 & 0,79 & $*(\beta>1)$ & \\
\hline & \multicolumn{4}{|c|}{ Abomaso } & \multirow[b]{2}{*}{0,3557} \\
\hline $\begin{array}{l}\text { Santa Inês } \\
\text { Bergamácia }\end{array}$ & $\begin{array}{l}0,4862 \\
0,5929\end{array}$ & $\begin{array}{l}0,063 \\
0,097\end{array}$ & $\begin{array}{l}0,71 \\
0,78\end{array}$ & $\begin{array}{ll}* * & (\beta<1) \\
* * & (\beta<1)\end{array}$ & \\
\hline \multirow[t]{2}{*}{ Equação geral } & \multicolumn{4}{|c|}{$\ln Y=-3,8398+0,5194 \ln X$} & \\
\hline & \multicolumn{4}{|c|}{ Omaso } & \multirow[b]{2}{*}{$0,0397 \quad\left(^{*}\right)$} \\
\hline Santa Inês & 0,6252 & 0,2604 & 0,20 & $\begin{array}{c}* \quad(\beta<1) \\
* * \quad(\beta>1)\end{array}$ & \\
\hline
\end{tabular}

** $\mathrm{P}<0,01 ; * \mathrm{P}<0,05$.

tipo de crescimento dos órgãos, é a seguinte: coração, cabeça e rins como órgãos precoces; pulmões, baço, intestino delgado e sangue como de crescimento intermediário; pele, fígado, pâncreas, intestino grosso e estômagos como tardios.

Osório et al. (1996) verificaram que pesos de cabeça, patas, vísceras, coração, pulmão+traquéia, baço, fígado e rins de animais abatidos com aproximadamente 123 dias de idade são maiores na raça Texel, em comparação às raças Merino, Ideal, Corriedale e Romney Marsh.

De acordo o teste $\mathrm{T}$, não houve diferença estatística entre raças (Tabela 6) para acúmulo de gordura com o

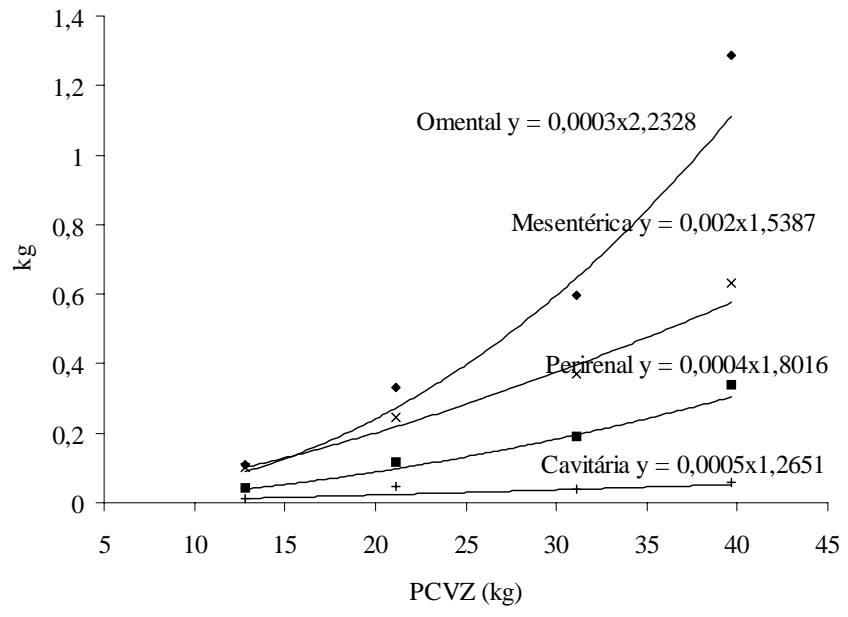

Figura 5 - Equação geral do crescimento alométrico das deposições de gordura omental, mesentérica, perirenal e cavitária de cordeiros Santa Inês em relação ao peso corporal vazio (PCVZ).

aumento do peso do animal; no entanto, de acordo com o teste F, os cordeiros Santa Inês apresentaram maior deposição média de gordura mesentérica ( $375 \mathrm{~g})$ e cavitária (40 g) que os Bergamácia (262 g) e (37 g), ou seja, provavelmente, os cordeiros Santa Inês converteram parte da energia da dieta para os depósitos de gordura envolta dos intestinos e rins.

A gordura é um fator que influencia na determinação do peso ótimo de abate, por ser, indiscutivelmente, o tecido mais variável da carcaça e varia não somente variando em quantidade, como também na forma de deposição, influenciando diretamente no processo de crescimento.

Tabela 6 - Deposição das gorduras omental, mesentérica, cavitária e perirenal em cordeiros Santa Inês e Bergamácia abatidos em diferentes pesos

\begin{tabular}{|c|c|c|c|c|c|}
\hline Peso de abate & PCVZ* & Omental & Mesentérica & Cavitária & Perirenal \\
\hline \multicolumn{6}{|l|}{ Santa Inês } \\
\hline $\begin{array}{l}15 \\
25 \\
35 \\
45\end{array}$ & $\begin{array}{l}12,83^{(0,35)} \\
20,82^{(0,25)} \\
30,89^{(0,30)} \\
39,79^{(0,62)}\end{array}$ & $\begin{array}{l}0,131^{(0,03)} \\
0,390^{(0,06)} \\
0,610^{(0,10)} \\
1,391^{(0,21)}\end{array}$ & $\begin{array}{l}0,106^{(0,01)} \\
0,258^{(0,02)} \\
0,406^{(0,05)} \\
0,731^{(0,08)}\end{array}$ & $\begin{array}{l}0,013^{(0,00)} \\
0,052^{(0,02)} \\
0,032^{(0,00)} \\
0,061^{(0,00)}\end{array}$ & $\begin{array}{l}0,052^{(0,00)} \\
0,125^{(0,01)} \\
0,191^{(0,02)} \\
0,377^{(0,04)}\end{array}$ \\
\hline \multicolumn{6}{|l|}{ Bergamácia } \\
\hline $\begin{array}{l}15 \\
25 \\
35 \\
45\end{array}$ & $\begin{array}{l}12,91^{(0,35)} \\
21,86^{(0,54)} \\
31,47^{(0,61)} \\
39,41^{(0,37)}\end{array}$ & $\begin{array}{l}0,070^{(0,01)} \\
0,210^{(0,02)} \\
0,570^{(0,05)} \\
1,083^{(0,11)}\end{array}$ & $\begin{array}{l}0,096^{(0,01)} \\
0,220^{(0,00)} \\
0,296^{(0,01)} \\
0,436^{(0,02)}\end{array}$ & $\begin{array}{l}0,012^{(0,00)} \\
0,032^{(0,00)} \\
0,053^{(0,00)} \\
0,051^{(0,00)}\end{array}$ & $\begin{array}{l}0,027^{(0,00)} \\
0,096^{(0,02)} \\
0,195^{(0,01)} \\
0,265^{(0,01)}\end{array}$ \\
\hline \multicolumn{6}{|l|}{ Raça } \\
\hline $\begin{array}{l}\text { Santa Inês } \\
\text { Bergamácia } \\
\text { Prob > F' } \\
\text { Prob > }\end{array}$ & $\begin{array}{c}26,08^{(2,13)} \\
26,41^{(3,01)} \\
0,9506 \\
0,9298\end{array}$ & $\begin{array}{c}0,630^{(0,12)} \\
0,483^{(0,11)} \\
0,3288 \\
0,3833\end{array}$ & $\begin{array}{c}0,375^{(0,05)} \\
0,262^{(0,03)} \\
0,0193 \\
0,0947\end{array}$ & $\begin{array}{c}0,040^{(0,00)} \\
0,037^{(0,00)} \\
0,0373 \\
0,7448\end{array}$ & $\begin{array}{c}0,186^{(0,02)} \\
0,146^{(0,02)} \\
0,2476 \\
0,3153\end{array}$ \\
\hline
\end{tabular}

*PCVZ - peso do corpo vazio. 
A diferença nos valores dos coeficientes indica intensidades diferentes de crescimento (Tabela 7): em ordem crescente: cavitária $(\beta>1,26)$, mesentérica $(\beta>1,53)$, perirenal $(\beta>1,80)$ e omental $(\beta>2,32)$.

Não houve diferença entre os tipos de desenvolvimento dos depósitos de gordura dos cordeiros Santa Inês e Bergamácia. Deposição tardia de gordura era esperada (Figura 5), pois a gordura é um tecido que inicia seu ritmo intenso de deposição no corpo depois de determinado tempo de vida ou por influência nutricional. Portanto, o tipo de desenvolvimento não diferenciou os depósitos de gordura, e sim o ritmo em que se desenvolveram.

A quantidade e a distribuição da gordura podem influenciar o rendimento da carcaça. Segundo Berg \& Butterfield (1976), o estudo do processo de crescimento da gordura poderia ser simplificado se fossem considerados os depósitos adiposos da carne e os internos do corpo, separadamente.

Os valores médios das cavidades torácica (CTOR) e abdominal (CABD) (Tabela 8) evidenciam, pelo teste $\mathrm{T}$, a diferença entre raças para os pesos médios da cavidade torácica; no entanto, os valores de probabilidade de F não detectam diferença estatística entre as raças nem para a CTOR nem para CABD. O mesmo comportamento foi verificado para as partes integrantes (PICAR) e não-integrantes da carcaça (PNCAR) dos cordeiros.

No valor médio da cavidade torácica estavam incluídos pulmões, esôfago, traquéia e coração, enquanto a CABD foi composta pelo rúmen/retículo, omaso, abomaso, gordura omental, intestino delgado, intestino grosso, gordura mesentérica, fígado, baço e pâncreas.
Mahendrakar et al. (1988) verificaram que cordeiros com a mesma idade, mas com diferentes pesos vivos (14,5 e 22,7 kg PV), apresentaram diferentes proporções de fígado $(2,42$ e $2,16 \%)$; rins $(0,34$ e $0,24 \%)$; sangue $(3,24$ e

Tabela 7 - Coeficiente de alometria ( $\beta$ ) das deposições de gordura de cordeiros Santa Inês e Bergamácia

\begin{tabular}{|c|c|c|c|c|c|}
\hline \multirow[b]{2}{*}{ Raça } & \multicolumn{4}{|c|}{ Gordura omental } & \multirow[b]{2}{*}{ Prob > F' } \\
\hline & $\beta$ & ep & $\mathrm{R}^{2}$ & $\begin{array}{c}\text { Prob }>|T| \\
\text { Ho: } \beta=1\end{array}$ & \\
\hline Santa Inês & 2,1157 & 0,2363 & 0,77 & $* *(\beta>1)$ & \multirow{2}{*}{0,3052} \\
\hline Bergamácia & 2,0771 & 0,1561 & 0,82 & $* *(\beta>1)$ & \\
\hline \multirow[t]{2}{*}{ Equação geral } & \multicolumn{4}{|c|}{$\ln Y=-8,0957+2,2328 \ln X$} & \\
\hline & \multicolumn{4}{|c|}{ Gordura mesentérica } & \multirow{3}{*}{0,1266} \\
\hline Santa Inês & 1,657 & 0,1412 & 0,85 & $* *(\beta>1)$ & \\
\hline Bergamácia & 1,3105 & 0,1205 & 0,91 & $* *(\beta>1)$ & \\
\hline \multirow[t]{2}{*}{ Equação geral } & \multicolumn{4}{|c|}{$\ln Y=-6,2146+1,5387 \ln X$} & \\
\hline & \multicolumn{4}{|c|}{ Gordura cavitária } & \multirow{3}{*}{0,4933} \\
\hline Santa Inês & 1,1777 & 0,2336 & 0,53 & $* *(\beta>1)$ & \\
\hline Bergamácia & 1,4478 & 0,2836 & 0,72 & $* *(\beta>1)$ & \\
\hline \multirow[t]{2}{*}{ Equação geral } & \multicolumn{4}{|c|}{$\ln Y=-7,5059+1,2651 \ln X$} & \\
\hline & \multicolumn{4}{|c|}{ Gordura perirenal } & \multirow{3}{*}{0,1042} \\
\hline Santa Inês & 1,669 & 0,1547 & 0,83 & $* *(\beta>1)$ & \\
\hline Bergamácia & 2,094 & 0,1752 & 0,93 & $* *(\beta>1)$ & \\
\hline Equação geral & \multicolumn{4}{|c|}{$\ln Y=-7,7847+1,8016 \ln X$} & \\
\hline
\end{tabular}

Tabela 8 - Valores médios dos componentes das cavidades torácica e abdominal e das partes integrantes e não-integrantes da carcaça de cordeiros Santa Inês e Bergamácia abatidos em diferentes pesos

\begin{tabular}{|c|c|c|c|c|c|}
\hline Peso de abate & $\mathrm{PCVZ} *$ & Cavidade torácica & Cavidade abdominal & $\begin{array}{c}\text { Partes integrantes } \\
\text { da carcaça }\end{array}$ & $\begin{array}{c}\text { Partes não-integrantes } \\
\text { da carcaça }\end{array}$ \\
\hline \multicolumn{6}{|l|}{ Santa Inês } \\
\hline 15 & $12,83^{(0,35)}$ & $0,398^{(0,03)}$ & $1,756^{(0,12)}$ & $3,223^{(0,13)}$ & $3,006^{(0,08)}$ \\
\hline 25 & $20,82^{(0,25)}$ & $0,523^{(0,02)}$ & $2,790^{(0,07)}$ & $5,436^{(0,08)}$ & $3,806^{(0,05)}$ \\
\hline 35 & $30,89^{(0,30)}$ & $0,725^{(0,01)}$ & $3,763^{(0,16)}$ & $7,956^{(0,11)}$ & $7,012^{(0,21)}$ \\
\hline 45 & $39,79^{(0,62)}$ & $0,753^{(0,02)}$ & $5,086^{(0,22)}$ & $10,770^{(0,09)}$ & $8,300^{(0,27)}$ \\
\hline \multicolumn{6}{|l|}{ Bergamácia } \\
\hline 15 & $12,91^{(0,35)}$ & $0,335^{(0,01)}$ & $1,340^{(0,14)}$ & $3,226^{(0,09)}$ & $3,382^{(0,13)}$ \\
\hline 25 & $21,86^{(0,54)}$ & $0,493^{(0,06)}$ & $2,623^{(0,08)}$ & $5,300^{(0,07)}$ & $5,609^{(0,07)}$ \\
\hline 35 & $31,47^{(0,61)}$ & $0,696^{(0,06)}$ & $3,403^{(0,09)}$ & $7,992^{(0,16)}$ & $7,590^{(0,34)}$ \\
\hline 45 & $39,41^{(0,37)}$ & $0,686^{(0,03)}$ & $4,596^{(0,11)}$ & $10,558^{(0,49)}$ & $9,817^{(0,33)}$ \\
\hline \multicolumn{6}{|l|}{ Raça } \\
\hline Santa Inês & $26,08^{(2,13)}$ & $0,600^{(0,03)}$ & $3,349^{(0,26)}$ & $6,846^{(0,58)}$ & $5,531^{(0,46)}$ \\
\hline Bergamácia & $26,41^{(3,01)}$ & $0,553^{(0,04)}$ & $2,990^{(0,36)}$ & $6,769^{(0,83)}$ & $6,599^{(0,72)}$ \\
\hline Prob > F' & 0,9506 & 0,7462 & 0,9115 & 0,9403 & 0,6581 \\
\hline Prob > & 0,9298 & 0,0495 & 0,3602 & 0,9405 & 0,2292 \\
\hline
\end{tabular}

*PCVZ - peso do corpo vazio. 
$2,75 \%)$ e patas $(3,13$ e 2,60\%), respectivamente, em relação ao peso vivo e que os animais que apresentaram as maiores proporções foram os mais leves.

As cavidades torácica $(\beta=0,635)$ e abdominal $(\beta=0,963)$, nas duas raças estudadas apresentaram ritmo de crescimento menor que o do peso corporal vazio (Tabela 9), ou seja, o ritmo de crescimento passou a ser lento à medida que aumentou o peso vivo. Esse resultado confirma que o trato gastrintestinal e suas partes apresentam, de forma geral, crescimento heterogônico negativo, ou seja, desenvolvimento relativo precoce em relação ao peso corporal vazio.

Não foi verificada diferença no tipo de desenvolvimento das cavidades das duas raças, o que difere dos relatos de Pires et al. (2000) de que as raças de ovinos apresentam maturação fisiológica em distintas idades e que a velocidade de crescimento dos órgãos difere entre raças, assim como os tamanhos à maturidade. No entanto,

Tabela 9 - Coeficientes alométricos da cavidade abdominal e torácica dos cordeiros Santa Inês e Bergamácia abatidos com diversos pesos

\begin{tabular}{|c|c|c|c|c|c|}
\hline \multirow[b]{2}{*}{ Raça } & \multicolumn{4}{|c|}{ Cavidade torácica } & \multirow[b]{2}{*}{ Prob > F' } \\
\hline & $\beta$ & ep & $\mathrm{R}^{2}$ & $\begin{array}{c}\text { Prob }>|T| \\
\text { Ho: } \beta=1\end{array}$ & \\
\hline SI & 0,6065 & 0,057 & 0,82 & $* * \quad(\beta<1)$ & \\
\hline BG & 0,7013 & 0,089 & 0,85 & $*(\beta<1)$ & \\
\hline \multirow[t]{2}{*}{ Equação geral } & \multicolumn{4}{|c|}{$\ln Y=-2,6009+0,6355 \ln X$} & \\
\hline & \multicolumn{4}{|c|}{ Cavidade abdominal } & \\
\hline Santa Inês & 0,9145 & 0,0572 & 0,92 & $\mathrm{~ns}$ & \\
\hline Bergamácia & 1,0734 & 0,076 & 0,94 & $\mathrm{~ns}$ & \\
\hline Equação geral & \multicolumn{4}{|c|}{$\ln Y=-1,9784+0,9635 \ln X$} & \\
\hline
\end{tabular}

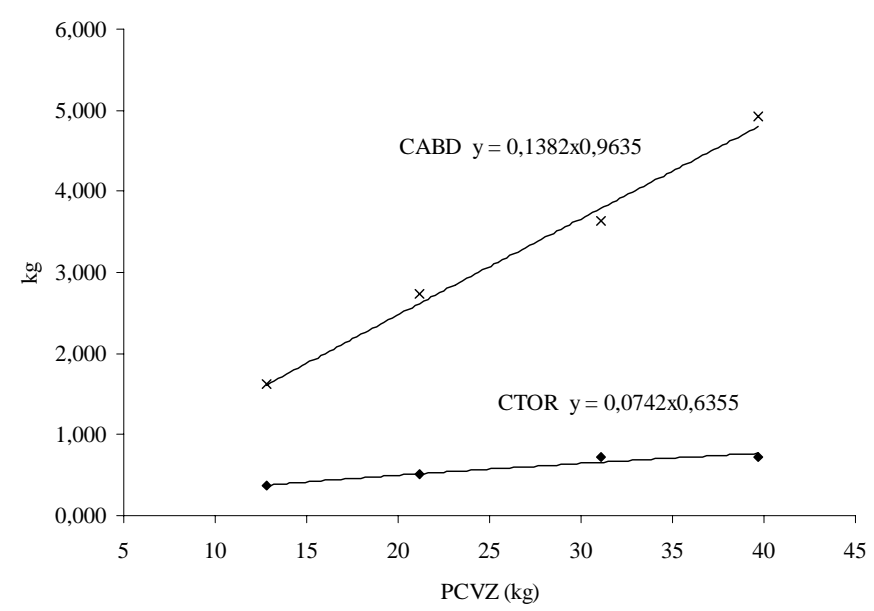

Figura 6 - Equação geral do crescimento alométrico dos componentes das cavidades torácica e abdominal de cordeiros Santa Inês e Bergamácia em relação ao peso corporal vazio (PCVZ). este desenvolvimento foi estimado em relação a diferentes pesos vivos e não com diferentes idades, o que pode ter provocado semelhança entre as raças.

Não houve diferença entre as raças quanto ao ritmo de crescimentos destas cavidades, no entanto, a cavidade torácica apresentou desenvolvimento precoce, e a cavidade abdominal, o mesmo ritmo de crescimento do peso corporal vazio (Figura 6).

Ainda, adotando-se o logaritmo da quantidade corporal de órgãos e vísceras, em função do logaritmo do peso do corpo vazio, realizou-se o estudo alométrico do que foi chamado parte integrante da carcaça e parte não-integrante da carcaça. Desta forma, verificou-se o desenvolvimento relativo de todo o corpo do animal (Tabela 10).

Nas partes integrantes da carcaça, estavam incluídos carcaça, rins, gordura cavitária e perirenal, enquanto, nas partes não-integrantes da carcaça. foram incluídos sangue, cabeça, pele e patas.

Os valores dos coeficientes alométricos encontrados permitiram classificar o crescimento das partes integrantes e não-integrantes da carcaça como isogônico, ou seja, estes constituintes corporais acompanham o desenvolvimento do corpo vazio (Figura 7).

Considerando os resultados encontrados, sugere-se uma classificação para os componentes corporais (Tabela 11) com base nos valores dos coeficientes alométricos dos constituintes corporais, órgãos e vísceras de cordeiros Santa Inês e Bergamácia na faixa de crescimento de 15 a $45 \mathrm{~kg}$ de peso vivo.

De acordo com os resultados encontrados neste trabalho, o fígado, pâncreas, abomaso, intestino delgado e intestino grosso podem ser considerados órgãos de desenvolvimento precoce, enquanto o baço de crescimento intermediário e o rúmen/retículo e omaso, de crescimento tardio.

Tabela 10 - Coeficiente de alometria $(\beta)$ das partes integrantes e não-integrantes da carcaça de cordeiros Santa Inês e Bergamácia

\begin{tabular}{|c|c|c|c|c|c|}
\hline \multirow[b]{2}{*}{ Raça } & \multicolumn{4}{|c|}{ Partes integrantes da carcaça } & \multirow[b]{2}{*}{ Prob > F' } \\
\hline & $\beta$ & ep & $\mathrm{R}^{2}$ & $\begin{array}{c}\text { Prob }>|T| \\
\text { Ho: } \beta=1\end{array}$ & \\
\hline Santa Inês & 1,0530 & 0,0227 & 0,98 & ns & \\
\hline Bergamácia & 0,9361 & 0,0391 & 0,98 & ns & \\
\hline Equação geral & \multicolumn{4}{|c|}{$\ln Y=-1,5186+1,074 \ln X$} & \\
\hline \multicolumn{6}{|c|}{ Partes não-integrantes da carcaça } \\
\hline Santa Inês & 0,9522 & 0,0531 & 0,93 & $\mathrm{~ns}$ & \\
\hline Bergamácia & 1,0517 & 0,0385 & 0,98 & ns & \\
\hline
\end{tabular}

Equação geral $\quad$ LnY $=-1,3362+0,9504 \ln X$

** $\mathrm{P}<0,01 ; * \mathrm{P}<0,05$. 


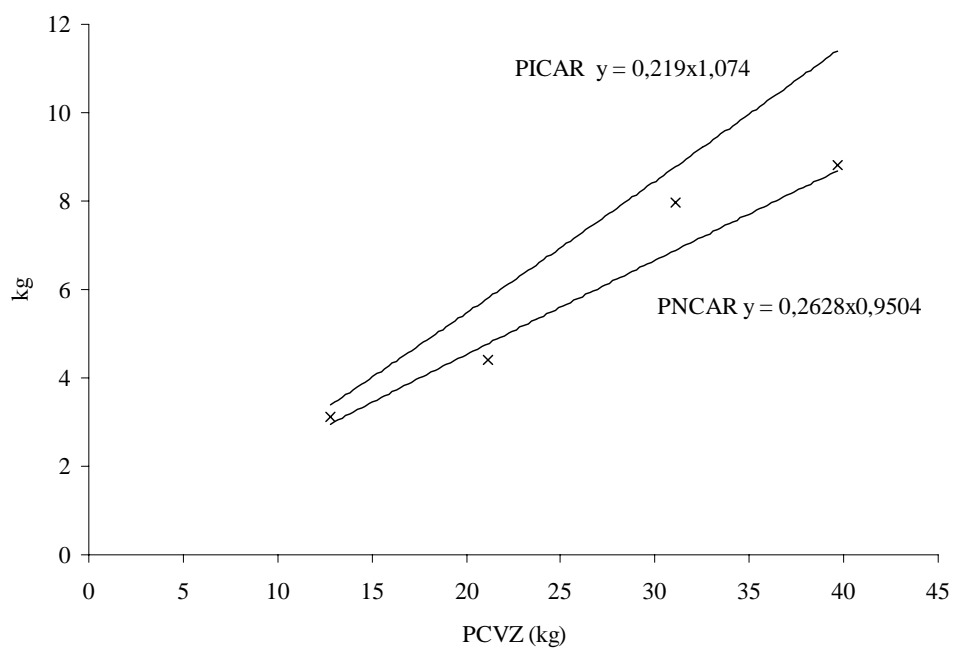

Figura 7 - Equação geral do crescimento alométrico das partes integrantes da carcaça (PICAR) e das partes não integrantes da carcaça (PNCAR), dos animais experimentais, em função do peso corporal vazio (PCVZ).

Tabela 11 - Classificação dos componentes corporais analisados neste capítulo em função do logaritmo do peso do corpo vazio

\begin{tabular}{|c|c|}
\hline Tipo de crescimento & Componente corporal \\
\hline $\begin{array}{l}\text { Heterogônico negativo } \\
\text { (desenvolvimento precoce) } \beta<1\end{array}$ & $\begin{array}{l}\text { Fígado, pâncreas, abomaso, intestino delgado, } \\
\text { intestino grosso e cavidade torácica }\end{array}$ \\
\hline $\begin{array}{l}\text { Isogônico } \\
\text { (desenvolvimento intermediário) } \beta=1\end{array}$ & $\begin{array}{c}\text { Baço, cavidade abdominal, partes integrantes da carcaça } \\
\text { Partes não-integrantes da carcaça }\end{array}$ \\
\hline $\begin{array}{l}\text { Heterogônico positivo } \\
\text { (desenvolvimento tardio) } \beta>1\end{array}$ & $\begin{array}{l}\text { Depósitos de gordura: cavitária, perirenal, } \\
\text { mesentérica e omental. Rúmen/retículo e omaso }\end{array}$ \\
\hline
\end{tabular}

\section{Conclusões}

Cordeiros Santa Inês apresentam desenvolvimento relativo precoce do omaso e retículo/rúmen, enquanto cordeiros Bergamácia apresentam crescimento heterogênico positivo desses órgãos, ou seja, o crescimento é tardio em relação ao do corpo vazio. Fígado, pâncreas, abomaso, intestino delgado, intestino grosso e cavidade torácica são considerados órgãos de crescimento heterogônico negativo ou precoce nas raças Santa Inês e Bergamácia. O baço, a cavidade abdominal e as partes integrantes e não-integrantes da carcaça nos cordeiros Santa Inês e Bergamácia apresentaram crescimento isogônico, ou seja, estes órgãos possuem mesmo ritmo de desenvolvimento do corpo vazio. No entanto, a deposição de gordura dos cordeiros Santa Inês tem comportamento heterogônico positivo, ou seja, é relativamente tardia em relação ao crescimento do corpo vazio.

\section{Literatura Citada}

AGRICULTURAL RESEARCH COUNCIL - ARC. The nutrient requirements of farm livestock. London, 1980. 351p.
BERG, R.T.; BUTTERFIELD, R.M. New concepts of cattle growth. Sydney: Sydney University Press, 1976. 240p.

DROVILLARD, J.S.; KLOPFENSTEIN, T.J.; BRITTON, R.A. Growth, body composition and visceral organ mass and metabolism in lambs during and after metaboliszable protein or met energy restrictions. Journal of Animal Science, v.69, n. 8, p.3357-3375, 1991.

HUIDOBRO, F.R.; VILLAPADIERNA, A. Estudios sobre crescimento y desarrollo en corderos de raza Manchega. 1992. 191f. Tesis (Doctoral) - Facultad de Veterinaria, Universidad Complutense, Madrid, 1992.

HUXLEY, J.S. Problems of relative growth. London: Methuen, 1932. $577 \mathrm{p}$.

JORGE, A.M.; FONTES, C.A.A.; PAULINO, M.F. et al. Efeito da raça zebuína e do peso de abate sobre o conteúdo corporal de macrolementos minerais. In: REUNIÃO ANUAL DA SOCIEDADE BRASILEIRA DE ZOOTECNIA, 35., 1998, Botucatu. Anais... Botucatu: Sociedade Brasileira de Zootecnia, 1998. p.218-220.

KOUAKOU, B.; GOETSCH, A.L.; PATIL, A.R. et al. Visceral organ mass in wethers consuming diets with different forages and grain levels. Livestock Production Science, v.47, p.125-137, 1997.

LYFORD, S.J. El rumiante fisiología digestive y nutrición. In:__ Crescimento y desarrollo del aparato digestivo de los ruminantes. Zaragoza: Acribia, 1993. p. 47-68.

MAHENDRAKAR, N.S.; KHABADE, V.S.; DANI, N.P. Studies on the effect of fattening on carcass characteristics and quality of meat from Bannur lambs. Journal Food Science Technologic, v.25, n.4, p.228-231, 1988. 
MARPLE, D.N. Principles of growth and development. In: GROWTH MANAGEMENT CONFERENCE, 1983, Indianapolis. Proceedings... Indianapolis: Integrated Marketing Communications, 1983. p.1-6.

MARQUES, J.A.; IWAYAMA, P.T.; PRADO, I.N. et al. Desempenho de novilhas búfalas terminadas em confinamento em resposta ao uso de promotor de crescimento ou de esferas de chumbo no útero. Arquivo Brasileiro de Medicina Veterinária e Zootecnia, v.58, n.6, p.1132-1138, 2006.

OH, J.H.; HUME, I.D.; TORREL, D.T. Developmente of microbial acitivity in the alimetary tract of lambs. Journal of Animal Science, v.35, n.2, p.450-459, 1972.

OLIVEIRA, M.A.T.; FONTES, C.A.A.; LANA, R.P. Biometria do trato gastrintestinal e área corporal de bovinos. Revista da Sociedade Brasileira Zootecnia, v.23, n.4. p.576-584, 1994.

OLIVEIRA, M.V.M.; PEREZ, J.R.O.; ALVES, E.L. et al. Avaliação da composição de cortes comerciais, componentes corporais e órgãos internos de cordeiros confinados e alimentados com dejetos de suínos. Revista Brasileira de Zootecnia, v.31, n.3, p.1459-1468, 2002 (supl.)

OSÓRIO, J.C.S.; SIEWRDT, F.; OSÓRIO, M.T.M. Desenvolvimento alométrico das regiões corporais em ovinos. Revista da Sociedade Brasileira de Zootecnia, v.24, n.2, p.326-333, 1995.

OSÓRIO, J.C.S.; OLIVEIRA, N.M.; JARDIM, P.O. et al. Produção de carne em ovinos de cinco genótipos. 2. Componentes do peso vivo. Ciência Rural, v.26, n.3, p.471-475, 1996.
OWENS, F.N.; GILL, D.R.; DAVID, S.S. et al. Review of some aspects of growth and development of feedlot cattle. Journal of Animal Science, v.73, n.10, p.3152-3172, 1995.

PERON, A.J.; FONTES, C.A.A.; LANA, R.P. et al. Tamanho de órgãos internos e distribuição da gordura corporal em novilhas de cinco grupos genéticos submetidos à alimentação restrita e "ad libitum". Revista Sociedade Brasileira de Zootecnia, v.22, n.5, p.813-819, 1993

PIRES, C.C.; SILVA, L.F.; FARINATTI, L.H.E. et al. Crescimento de cordeiros abatidos com diferentes pesos. 2. Constituintes corporais. Ciência Rural, v.30, n.5, p.869-873, 2000.

ROSA, G.T. Proporções e crescimento de osso, músculo, gordura e componentes não carcaça do peso vivo e crescimento das regiões da carcaça de cordeiros (as) em diferentes métodos de alimentação. 2000. 84f. Dissertação (Mestrado em Zootecnia) - Universidade Federal de Santa Maria, Santa Maria, 2000.

STATISTICAL ANALYSIS SYSTEM - SAS. SAS/ETS ${ }^{\circledR}$ : user's guide. Version 6. 2.ed. Cary: SAS Institute, 2000. (CD-ROM).

SILVA, L.F. Crescimento, composição corporal e exigências nutricionais de cordeiros abatidos com diferentes pesos. 1999. 64f. Dissertação (Mestrado em Zootecnia) - Universidade Federal de Santa Maria, Santa Maria, 1999.

SISSON, S.; GROSSMAN, J.D. Anatomia dos animais domésticos. 5.ed. Rio de Janeiro: Guanabara Koogan, 1986. v. $1,1334 \mathrm{p}$. 